\title{
Production and Properties of Short Jute and Short E-Glass Fiber Reinforced Polypropylene-Based Composites
}

\author{
Md Nuruzzaman Khan ${ }^{1,2}$, Juganta K. Roy ${ }^{2}$, Nousin Akter ${ }^{1,2}$, Haydar U. Zaman', Tuhidul Islam ${ }^{3}$, \\ Ruhul A. Khan ${ }^{*}$ \\ ${ }^{1}$ Nuclear and Radiation Chemistry Division, Institute of Nuclear Science and Technology, Bangladesh Atomic Energy Commission, \\ Dhaka, Bangladesh; ${ }^{2}$ Department of Applied Chemistry and Chemical Engineering, University of Dhaka, Dhaka, Bangladesh; ${ }^{3}$ De- \\ partment of Biochemical Engineering, Jacobs University, Bremen, Germany. \\ Email: *dr.ruhul_khan@yahoo.com
}

Received January $29^{\text {th }}, 2012$; revised March $2^{\text {nd }}, 2012$; accepted March $15^{\text {th }}, 2012$

\begin{abstract}
Short jute fiber ( $2-3 \mathrm{~mm}$ ) reinforced polypropylene PP-based composites (20\% fiber by weight) were fabricated using compression molding and the mechanical properties were evaluated. Tensile strength (TS), tensile modulus (TM), elongation at break (Eb\%), flexural strength (FS), flexural modulus (FM), impact strength (IS), and hardness of the composites were found to be $32 \mathrm{MPa}, 850 \mathrm{MPa}, 12 \%, 38 \mathrm{MPa}, 1685 \mathrm{MPa}, 18 \mathrm{~kJ} / \mathrm{m}^{2}$ and 96 shore-A, respectively. Then short E-glass fiber $(2-3 \mathrm{~mm})$ reinforced PP-based composites (20\% fiber by weight) were fabricated and mechanical properties were compared with short jute-based composites. Short jute-based composites showed excellent mechanical properties and comparable to short E-glass-based composites. Soil degradation test of both types of composites indicated that jute/PP composites significantly lost much of its mechanical properties but E-glass/PP composites retained major portion of its original integrity. Interfaces of the degraded composites were investigated by scanning electron microscopy and supported the biodegradation properties of jute/PP composites.
\end{abstract}

Keywords: Jute Fiber; E-Glass Fiber; Composites; Compression Molding; Polypropylene

\section{Introduction}

Composite materials are consisting of a polymer matrix and a reinforcing agent. Composites are versatile and convenient in diverse application such as automotive and aeronaut industry, constructional materials, civil and military applications and many more. Composite based on thermoplastic resins, are gained popularity due to their processing advantages [1]. The mechanical properties of thermoplastics are enhanced for specific application by incorporating different man made and natural fibers. The fiber dispersion in the thermoplastic composites is an important consideration to achieve consistency in the product. Thermoplastic composites are flexible and strong and exhibit good physio-mechanical properties. However, the percentage of fiber loading is limited by the processability of the composite. Properties of the fibers, the aspect ratio of the fibers, and the fiber-matrix interface govern the properties of the composites. The surface adhesion between the fiber and the polymer plays an important role in the transmission of stress from matrix to the fiber and thus determine the performance of the composite $[2,3]$.

${ }^{*}$ Corresponding author.
Synthetic reinforcement fibers like glass, aramid, nylon and carbon have good physio-mechanical properties. Silica based E-glass fibers (54.3SiO2-15.2Al2O317.2CaO-4.7MgO-8.0BO-0.6Na2O) are widely used due to their low cost, availability and good insulation properties up to $815^{\circ} \mathrm{C}$. E-glass fiber reinforcement is often an attractive way to improve the mechanical properties of thermoplastics, the improvement being attributed to the excellent mechanical properties of the fibers and to the better adhesion between the fibers and the polymer matrix when surface treated fibers are used $[1,4]$.

Environmental concerns have resulted in a renewed interest in agro-based materials, and therefore issues such as recyclability and environmental safety are becoming increasingly important for the introduction of new materials and products. Nowadays there is a growing interest in the use of agro-fibers (jute, hemp, rice husk, abaca wheat straw, coir, kenaf, flax etc) as reinforcing components for thermoplastics, because they are more economical than the synthetic fibers. Secondly, as result of environmental care politics, which is particularly important in those countries where products from agricultural sources offer attractive and cheap alternative for devel- 
oping degradable materials. The combination of interesting mechanical and physical properties together with their environmentally friendly character has motivated a number of industrial sectors, notably the automotive industry, to consider these fibers as potential candidates to replace glass fibers in environmentally safe products. Jute is an attractive natural fiber for use as reinforcement in composite because of its excellent mechanical properties, low cost, renewable nature and much lower energy requirement for processing. It is produced in large scale in tropical area like Bangladesh, Indian and Latin America and it is already identified as potential candidate for reinforcing agent in composite fabrication. Jute fabrics are also called Hessian cloth. Jute composed of mainly $\alpha$-cellulose, hemicelluloses, and lignin. In addition, it contains minor constituents such as flats and waxes, inorganic and nitrogenous matters, and traces of pigments like $\beta$-carotene and Xanthophyls [5-7]. The main component of jute fiber is a hydrophilic glucan polymer consisting of a linear chain of $1,4-\beta-a$ hydroglucose unit. The crystalline regions of hydroxyl groups can form hydrogen bonds between parallel chains, thereby reducing the water absorption. The mechanical and physical properties of jute are highly inconsistent and are dependent upon geographic origin, climate, growth conditions, chemical composition (functional groups), molecular structure characteristics, and details of its physical state (above or below $\mathrm{Tg}$, nature and degree of crystallinity) and processing techniques. Several disadvantages of jute, such as poor wettability, poor fiber-matrix adhesion, intrinsic polarity due to the presence of hydroxyl and carboxyl groups in their structure, and low moisture resistance make it insufficient for proper reinforcement. To overcome this problem, many attempts, such as physical and chemicals treatments, lead to changes in the surface structure and surface energy of the fibers. Many researchers are working on jute fibers reinforced composites. Potential of jute fabrics as reinforcing material has proved by the researchers [8-11].

Thermoplastic composite is manufactured using potentially high performance resin such as polypropylene (PP), polyethylene (PE), polyvinyl chloride (PVC) etc. Among commodity thermoplastics, polypropylene (PP) possesses outstanding properties like low density, good flex life, sterilizability, good surface hardness, scratch resistance and very good abrasion resistance [12-14]. The high crystalline structure of PP imparts a relatively high melting point $\left(160^{\circ} \mathrm{C}-170^{\circ} \mathrm{C}\right)$ and softening point (above $149^{\circ} \mathrm{C}$ ), stiffness, strength, and hardness. It has been found to have a rare combination of excellent physical, mechanical, thermal, electrical and chemical properties. The specific gravity of PP varies from 0.90 to 0.91 and so it is the lightest plastic material. It is an excellent ma- terial for electrical applications because of outstanding combination of good thermal properties, low moisture pickup and good dielectric properties even at high frequency because of non-polar in nature. PP is also very suitable for filling, reinforcing and blending. PP with fibrous natural polymers of biomass origin is one of the most promising routes to create natural-synthetic polymer composites [15-17].

The aim of the present studies was to fabrication and mechanical characterization of short jute fiber and short E-glass fiber reinforced PP-based composites. Comparative studies were carried out between two types of composites. The soil degradation tests of the composites were performed. The degradation of the mechanical properties of jute fiber/PP composites were compared over the Eglass fiber/PP composites. Interfacial properties were investigated by scanning electron microscopy.

\section{Experimental}

\subsection{Materials}

Polypropylene (PP) was purchased from Polyolefin Company, Private Ltd., Singapore. Jute fibers were obtained from the Bangladesh Jute Research Institute (BJRI), Dhaka. E-glass fibers were purchased from Saint-Gobain Vetrotex, India.

\subsection{Composite Fabrication}

Polypropylene sheets of $0.25-0.30 \mathrm{~mm}$ thickness were prepared from granules of PP by pressing at $190^{\circ} \mathrm{C}$ for 1 min between two steel molds under 5 bar consolidation pressure in the heat press (Carver, INC, USA Model 3856). The molds were then cooled for $1 \mathrm{~min}$ in a separate press under 5 bar pressure at room temperature. The resulting PP sheet was cut into desired size for composite fabrication. Jute fibers and E-glass fibers were cut into small pieces (length was about $2-4 \mathrm{~mm}$ ). The digital images of jute (a) and E-glass (b) fibers are presented in Figure 1. Composites were prepared by sandwiching 4 layers of short jute fibers between 5 sheets of preweighted PP. The sandwich was then placed between two steel molds and heated at $190^{\circ} \mathrm{C}$ for 5 min to soften the polymer prior to pressing 5 bar pressure for $5 \mathrm{~min}$. The fiber weight fraction of the composites was calculated to be about $20 \%$. Short E-glass fibers reinforced PP matrix composites ( $20 \%$ fiber by weight) were also fabricated using same parameters in the same heat press.

\subsection{Mechanical Testing of the Composites}

Tensile, flexural, charpy impact and hardness (shore A) tests were conducted. For each test and type of composites, five specimens were tested and the average values 


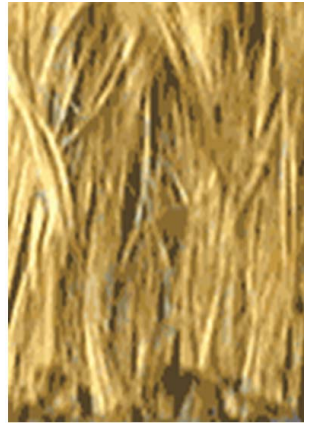

(a)

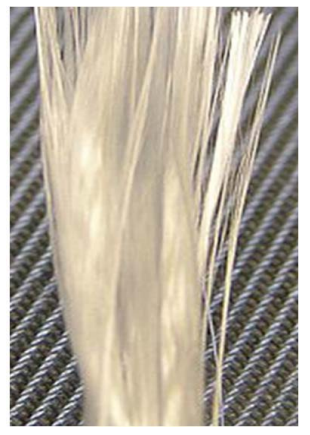

(b)
Figure 1. The digital images of jute (a) and E-glass (b) fibers.

were reported.

\subsection{Tensile Test}

Tensile tests were conducted according to ASTM D 638-01 [19] using a Universal Testing Machine (Hounsfield series, model: INSTRON 1011, UK) with a crosshead speed of $10 \mathrm{~mm} / \mathrm{min}$. The dimensions of the test specimen were (ISO 14125): $60 \mathrm{~mm} \times 15 \mathrm{~mm} \times 2 \mathrm{~mm}$.

\subsection{Flexural Test}

Static flexural tests were carried out according to ASTM D 790-00 [20] using the same testing machine mentioned above at the same cross-head speed. The flexural strength and modulus were calculated using the following equations:

$$
\begin{aligned}
& \text { Flexural strength, } \sigma_{f}=\frac{3 P L}{2 b d^{2}} \\
& \text { Flexural modulus, } E=\frac{L^{3} m}{4 b d^{3}}
\end{aligned}
$$

where $P$ is the maximum applied load, $L$ is the length of support span, $\mathrm{m}$ is the slope of the tangent, and $\mathrm{b}$ and $\mathrm{d}$ are the width and thickness of the specimen respectively.

\subsection{Charpy Impact Test}

Dynamic charpy impact tests were conducted on unnotched mode composite specimens according to ASTM D 6110-97 using a Impact tester (MT-3016, Pendulum type, Germany).

\subsection{Hardness Test}

The hardness of the composites was measured using a HPE Shore-A Hardness Tester (model 60578, Germany) according to ASTM D785-98 [6].

\subsection{Water Uptake of the Composites}

Composite samples $\left(20 \times 10 \times 2 \mathrm{~mm}^{2}\right)$ were immersed in a static water bath at $25^{\circ} \mathrm{C}$ for different time periods (up to $60 \mathrm{~h}$ ). Before immersion in water, the specimens were dried in an oven at $105^{\circ} \mathrm{C}$, cooled in a desiccators using silica gel and weighed. After certain periods of time, samples were taken out from the bath and wiped using tissue paper, then weighed. Water uptake was determined by the subtraction from final weight to initial weight.

\subsection{Soil Degradation Tests of the Composites}

Composite samples were buried in soil (having at least $25 \%$ moisture) for different periods of time. After a certain period, samples were withdrawn carefully, washed with distilled water and dried at $105^{\circ} \mathrm{C}$ for 6 hours and kept at room temperature for 24 hour and then measured the mechanical properties.

\subsection{Scanning Electron Microscopic Analysis}

Jute fibers and E-glass fibers were examined by Philips scanning electron microscope (SEM) at an accelerating voltage of $10 \mathrm{kV}$. SEM specimens were sputtercoated with gold. Fracture sides of the composites (after bending tests) were also observed using SEM.

\section{Results and Discussion}

\subsection{Mechanical Properties of the Composites}

Short jute fiber and short E-glass fiber reinforced popypropylene composites ( $20 \%$ fiber by weight) were made by compression molding. The mechanical properties such as tensile, flexural, impact and hardness of polypropylene (PP), jute fiber/PP and E-glass fiber/PP composites were evaluated and compared. The results are presented in Tables 1-2. It was found that tensile strength (TS), tensile modulus (TM), elongation at break (\%), flexural strength (FS), flexural modulus (FM), impact strength (IS) and hardness of the PP sheet were found to be $21 \mathrm{MPa}, 640 \mathrm{MPa}, 340 \%, 28 \mathrm{MPa}, 1040$ $\mathrm{MPa}, 4.47 \mathrm{KJ} / \mathrm{m}^{2}$ and 95 Shore A, respectively. Both jute/PP and E-glass/PP composites gained a significant improvement of the mechanical properties. Both type of fibers successfully reinforced with PP matrix. The TS and TM of short jute composites increased to $52 \%$ and $33 \%$ respectively than that of the matrix PP. It was also found that flexural strength, flexural modulus and impact strength also improved 35, 62 and 302\% respectively over the matrix material PP. On the other hand, percentage elongation at break $(\mathrm{Eb} \%)$ was reduced drastically because of low $\mathrm{Eb} \%$ of the fibers compared to PP. Short jute based composites showed relatively similar TS, BS, IS and hardness compared to short E-glass composites. Similarly, short E-glass reinforced PP-based composites possessed a significant improvement of TS, TM, FS, FM 
Table 1. Tensile and flexural properties of polypropylene sheet and the composites ( $20 \%$ fiber by weight).

\begin{tabular}{|c|c|c|c|c|c|}
\hline \multirow{3}{*}{ Material } & \multicolumn{5}{|c|}{ Tensile and Flexural Properties } \\
\hline & \multicolumn{3}{|c|}{ Tensile Properties } & \multicolumn{2}{|c|}{ Flexural Properties } \\
\hline & Strength (MPa) & Modulus (MPa) & Elongation at Break (\%) & Strength (MPa) & Modulus (MPa) \\
\hline Polypropylene (PP) & $21 \pm 0.8$ & $640 \pm 14$ & $340 \pm 30$ & $28 \pm 1.2$ & $1040 \pm 30$ \\
\hline Short Jute Fiber/PP Composite & $32 \pm 0.3$ & $850 \pm 10$ & $12 \pm 2$ & $38 \pm 0.3$ & $1685 \pm 23$ \\
\hline Short E-glass Fiber/PP Composite & $31 \pm 0.4$ & $790 \pm 15$ & $38 \pm 3$ & $36 \pm 0.8$ & $1265 \pm 20$ \\
\hline
\end{tabular}

Table 2. Impact strength and hardness of the polypropylene sheet and the composites ( $20 \%$ fiber by weight).

\begin{tabular}{ccc}
\hline Material & \multicolumn{1}{c}{ Impact Strength and Hardness } \\
\cline { 2 - 3 } & Impact Strength $\left(\mathrm{kJ} / \mathrm{m}^{2}\right)$ & Hardness (shore-A) \\
\hline Polypropylene (PP) & $4.47 \pm 0.4$ & $95 \pm 1$ \\
Short Jute Fiber/PP Composite & $18 \pm 0.4$ & $96 \pm 0.5$ \\
Short E-glass Fiber/PP Composite & $18.5 \pm 0.3$ & $97 \pm 0.5$ \\
\hline
\end{tabular}

and IS compared to the matrix PP. Short E-glass composites showed $47 \%$ increase in TS and $23 \%$ increase in TM over that of the matrix PP. It was also found that FS, FM and IS also improved 35, 21 and 313\% respectively than that of the matrix material PP. It was also revealed that the percentage of elongation at break $(\mathrm{Eb} \%)$ of the composites reduced considerably than the matrix PP due to low $\mathrm{Eb} \%$ of the fibers compared to PP. Hardness (Shore-A) of the composites indicated that due to incorporation of short E-glass fibers inside PP, the hardness of the composite had almost similar properties. Since both PP and the E-glass fibers are hydrophobic in nature, the fiber matrix adhesion was expected to be excellent. This was reflected in the mechanical properties of the E-glass based composites. It was revealed that the jute composites found to be 3 and 5\% improvement of TS and FS over the E-glass fiber/PP composites. On the other hand the TM, FM of the short jute based composites is improved 7.5 and $33 \%$ higher than that of the E-glass/PP composites. Since density of E-glass is higher, so the volume of $20 \%$ E-glass fiber is smaller than that of jute fiber. It is suggesting that there was an almost similar stress transfer from matrix to the fibers and due to the relatively small volume of E-glass fibers in the composites; it may be showed similar strength compared to the jute composites. From this investigation, this is clear that jute composites gained huge mechanical properties over the matrix material and almost similar mechanical properties to short E-glass/PP composites.

\subsection{Water Uptake of the Composites}

In Figure 2, water uptake ( $\mathrm{wt} \%$ ) of the composites were plotted against soaking time (60 hrs). It was found that the jute composite showed poor water absorption characteristic. After $5 \mathrm{hr}$, jute composite absorbed only $0.5 \%$ water. It was found only $0.63 \%$ after 30 hours of soaking and become static with time. On the other hand, the water absorption of E-glass composite is very nominal with time. Jute is mainly built up with cellulose which is the

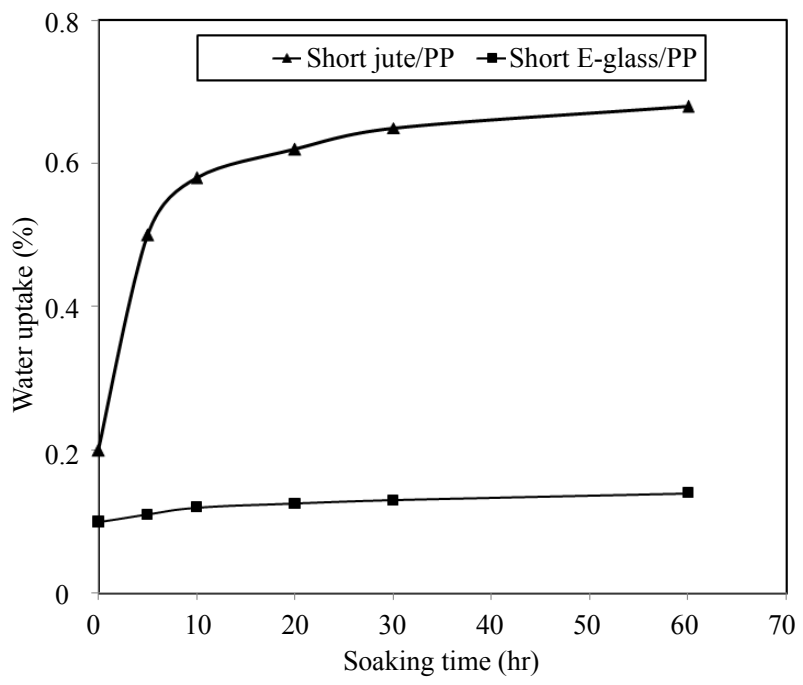

Figure 2. Water uptake (\%) by composites in aqueous media at room temperature $\left(25^{\circ} \mathrm{C}\right)$. 
hydrophilic glucan polymer. The elementary unit of jute is anhydro-d-glucose which contains three hydroxyl $(-\mathrm{OH})$ groups $[17,18,20]$. These hydroxyl groups in the cellulose structure account for the strong hydrophilic nature of jute. But the composites are reinforced with $20 \% \mathrm{wt}$ fraction of fibers. This small mass of fibers is responsible for poor water absorption of jute composites. During soaking, water penetrates from cutting edges of the composites and account for water absorption.

\subsection{Degradation Tests of the Composites}

Mechanical properties of the fabricated composites were evaluated and compared each other. The discontinuous fiber composites (jute fiber/PP and E-glass fiber/PP) were subjected to soil degradation at ambient condition for up to 24 weeks. Tensile strength (TS) and tensile modulus (TM) values are plotted against degradation time and are shown in Figures 3 and 4. It was clear that for short jute/PP composites, both TS and TM decreased phenomenally with time but for E-glass/PP, a very slow decreased was observed both for strength and modulus. After 6 weeks of soil degradation, jute composites lost almost $16 \%$ and $8 \%$ of TS and TM respectively. On the other hand, glass fiber composites lost only 1.3 and $1.7 \%$ of TS and TM respectively. With time jute composites showed phenomenon loss of strength and modulus. The losses of strength are 22 and 3\% respectively for jute/PP and glass/PP composites in 12 weeks. After 6 months of soil degradation, the short jute/PP composite showed a significant loss of strength but short E-glass fiber retained much of its strength. Jute composite lost $28 \%$ of its strength but that is only $3.2 \%$ for glass composites. In the same period short jute/PP composite lost almost

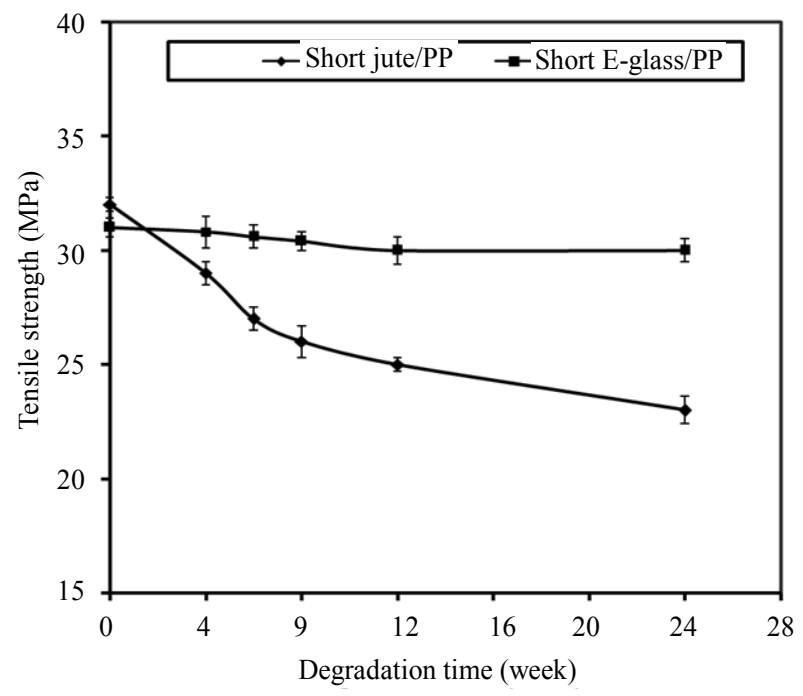

Figure 3. Degradation of tensile strength of the composites during soil degradation tests.

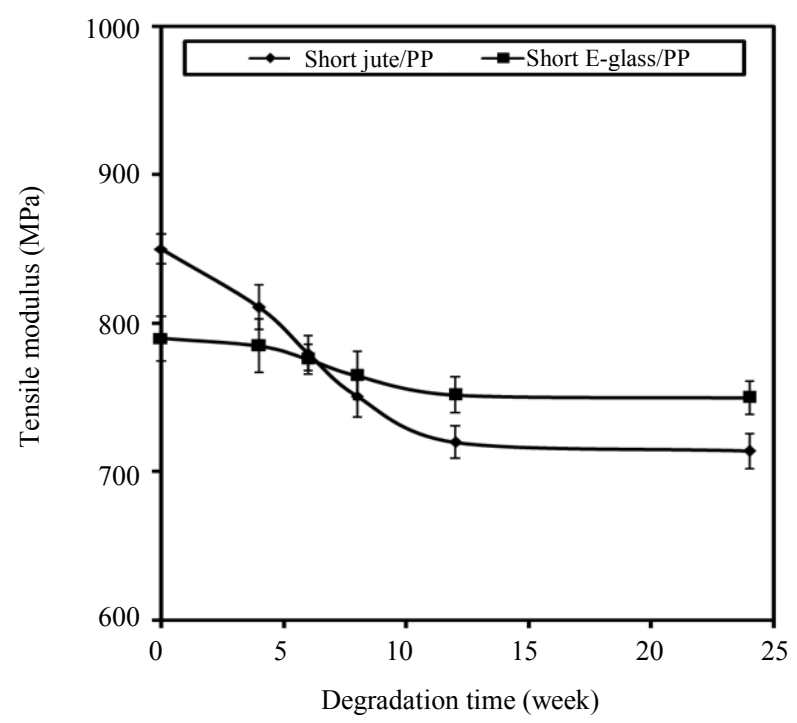

Figure 4. Degradation of tensile modulus of the composites during soil degradation tests.

$11 \%$ and short E-glass/PP lost $8 \%$ of modulus. This is clear that E-glass fiber composites retained much of its tensile properties than that of the jute composites during soil degradation. Jute is a natural biodegradable fiber and this fiber is lignocellulose based which absorbs water within a couple of minutes indicated its strong hydrophilic character. Cellulose has a strong tendency to degrade when buried in soil [18]. During soil degradation tests, water penetrates from the cutting edges of the composites in jute based samples and degradation of cellulose occurred in jute and as a result, the mechanical properties of the composites decreased significantly. But E-glass based composites are strongly hydrophobic and repel water thus kept much of its integrity during exposure to the soil. The change in flexural strength and modulus, with soil degradation time are shown in Figures 5-6 respectively. After 6 weeks of soil degradation, FS and FM of the jute/PP composites decrease significantly but E-glass/PP composites showed a little change. Jute composites lost 13 and 5\% of FS and FM respectively in that time. On contrary, E-glass composites showed 4 and $4.3 \%$ loss of FS and FM. After 12 weeks, the strength of jute composites decrease drastically but a slow change was observed for E-glass composites. The losses of FS and FM were found to be 21 and $10 \%$ respectively for jute composites but 5.5 and $6 \%$ for E-glass composites. Finally the strength and modulus of jute composites decreased almost 23 and $11 \%$ respectively after 6 months. On the other hand, E-glass composites showed only 5.8 and $6 \%$ loss of FS and FM respectively in the same period. The toughness of composite is usually affected by inter-laminar and interfacial parameters 


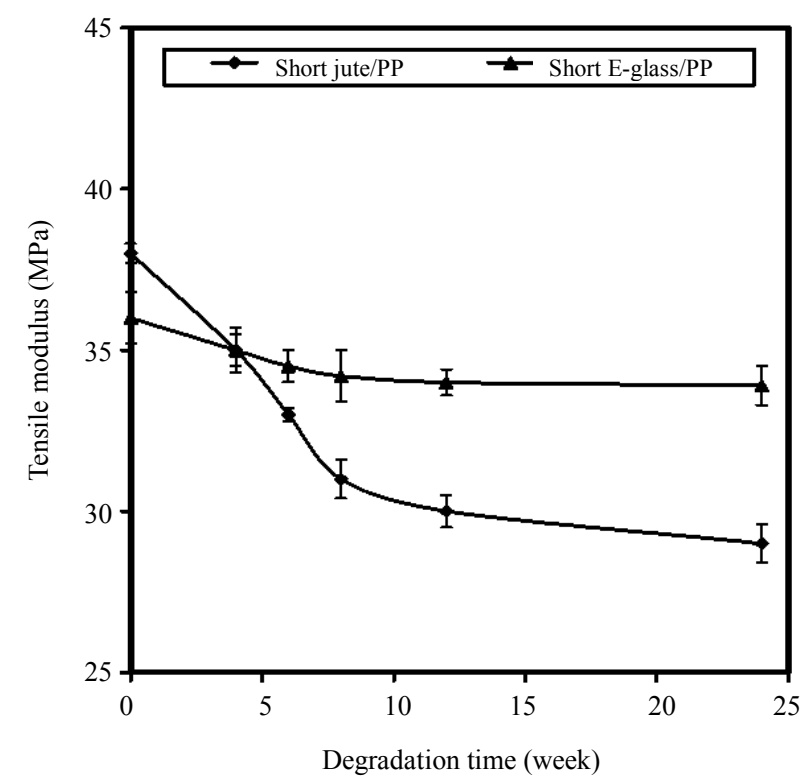

Figure 5. Degradation of flexural strength of the composites during soil degradation tests.

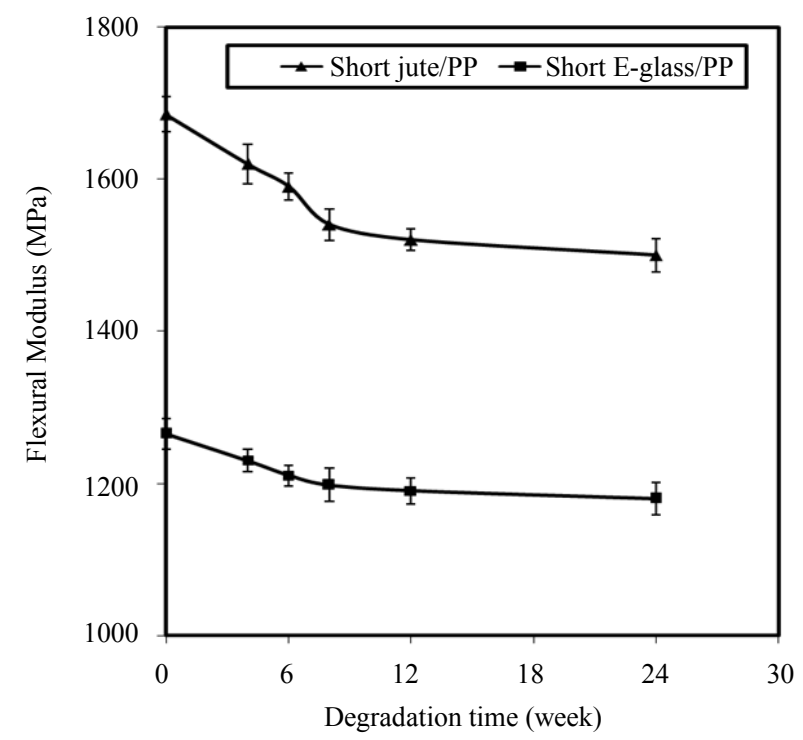

Figure 6. Degradation of flexural modulus of the composites during soil degradation tests.

and failure is observed due to fiber pull out, matrix fracture and fiber matrix de-bonding [19]. All of these are accelerated in soil degradation. The effects of soil degradation on the impact strengths of jute/PP and E-glass/ PP composites are shown in the Figure 7. The impact strength of jute composites decrease sharply in 12 weeks of soil degradation. The E-glass composites retained much of its impact strength than the jute composites during soil degradation test. Jute composite lost $11 \%$ of IS in 6 weeks but only 4\% was observed for E-glass composites. After 12 weeks of soil degradation, the IS of

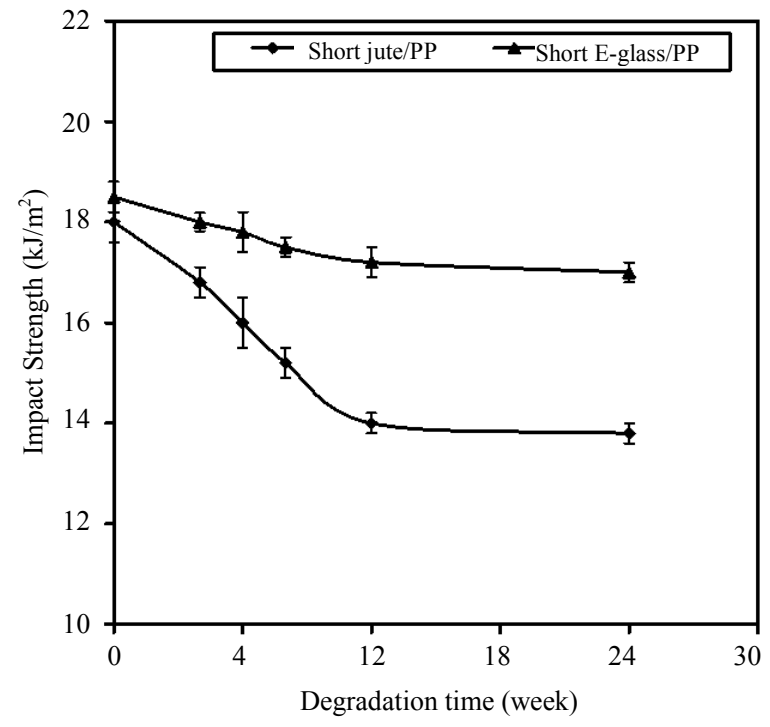

Figure 7. Degradation of impact strength of the composites during soil degradation tests.

jute composites reduced to $22 \%$ and that of E-glass composites was found to be 7\%. After 6 months, E-glass and jute composites showed little change in IS.

\subsection{Interfacial Properties of the Composites}

To investigate the degradation behavior of fibers inside matrix in composites, scanning electron microscopic (SEM) studies were carried out. Six months soil degraded SEM images of the fracture surfaces of jute fibers/PP and E-glass fibers/PP-based composites are presented in Figures 8(a) and (b). For jute/PP composites (Figure $\mathbf{8 ( a )}$ ), it is clearly indicated that major fraction of jute fibers were degraded but for short E-glass fibers (Figure 8(b)) were almost intact. After degradation tests, bond between jute and PP was lost and as a result mechanical properties decreased significantly. On the other hand, bond between E-glass and PP was good enough to retain its mechanical strength. A large gap was evident in jute/PP composite. This is reflected in the mechanical properties described in the above section. From the comparative studies of the mechanical properties between jute/PP and E-glass/PP composites, it was found that the mechanical properties of E-glass/PP composites retained much of its mechanical integrity than that of the jute/PP composites. The jute/PP composites supported the biodegradation properties of jute fibers.

\section{Conclusion}

Short jute fiber/PP and short E-glass fiber/PP-based composites ( $20 \%$ fiber by weight) were successfully fabricated using compression molding and the mechanical properties were evaluated. Short jute based composites 


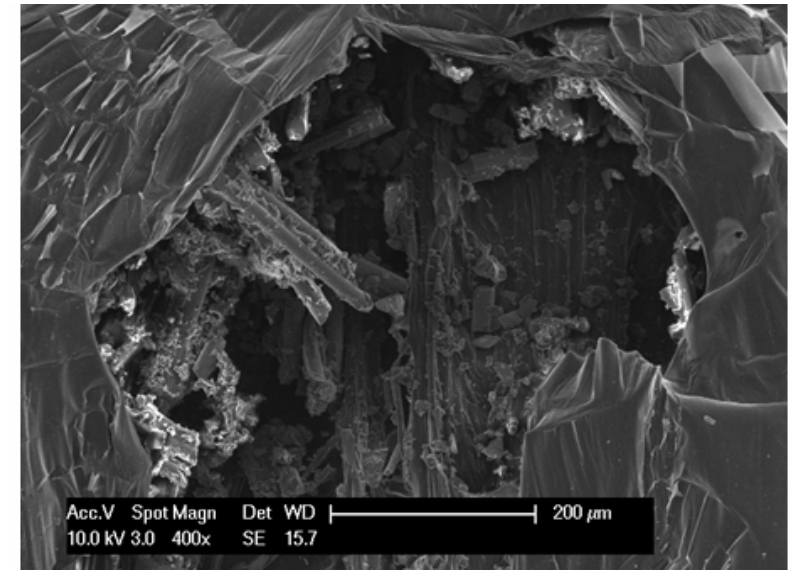

(a)

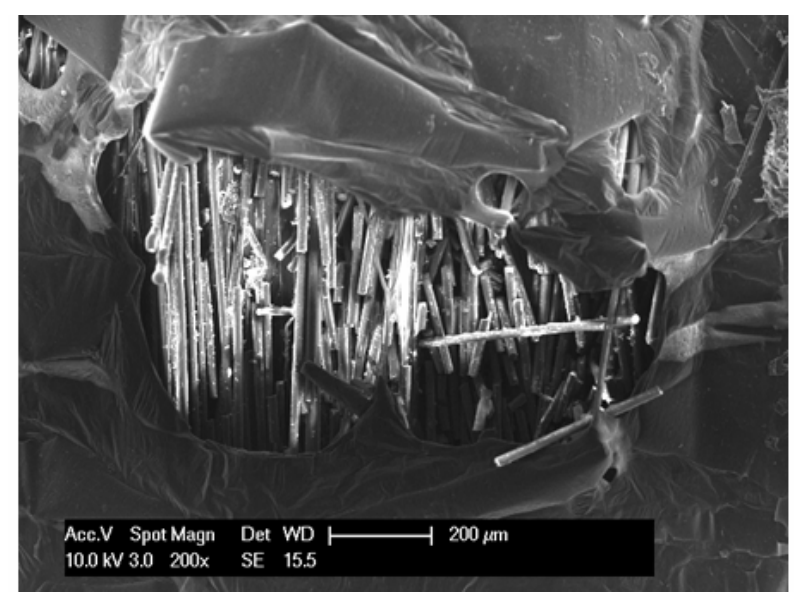

(b)

Figure 8. SEM images of the degraded interface of short jute fibers (a) and short E-glass fibers (b) reinforced PPbased composite.

showed almost similar mechanical strength and hardness compared to short E-glass-based composites. After soil degradation test, the jute/PP composites significantly lost much of its mechanical properties. On the contrary, the E-glass/PP composites retained much of its mechanical properties after degradation test.

\section{REFERENCES}

[1] H.-Q. Xie, S. Zhang and D. Xie, "An Efficient Way to Improve the Mechanical Properties of Polypropylene/Short Glass Fiber Composites," Journal of Applied Polymer Science, Vol. 96, No. 4, 2005, pp. 1414-1420. doi:10.1002/app.21575

[2] D. N. Saheb and J. P. Jog, "Natural Fiber Polymer Composites: A Review," Advances in Polymer Technology, Vol. 18, No. 4, 1999, pp. 351-363.

doi:10.1002/(SICI) 1098-2329(199924)18:4<351::AID-A DV6>3.0.CO;2-X

[3] S. S. Morye and R. P. Wool, "Mechanical Properties of
Glass/Flax Hybrid Composites Based on a Novel Modified Soybeam Oil Matrix Material," Polymer Composites, Vol. 26, No. 4, 2005, pp. 408-416. doi:10.1002/pc.20099

[4] M. T. Run, H. Z. Song, Y. P. Hao, X. M. Hu and C. G. Yao, "Preparation, Structure, and Properties of the PTT/SGF Composites," Polymer Composites, Vol. 30, No. 6, 2008, pp. 776-781. doi:10.1002/pc.20617

[5] M. A. Khan, M. Hossain and K. M. I. Ali, "Jute Composite with MMA by Gamma and UV Radiations in the Presence of Additives," Journal of Applied Polymer Science, Vol. 74, No. 4, 1999, pp. 900-906. doi:10.1002/(SICI)1097-4628(19991024)74:4<900::AIDAPP16>3.0.CO;2-J

[6] R. A. Khan, M. E. Haque, M. A. Khan, H. U. Zaman, K. J. F. Mohamad and A. Ahmad, "Studies on the Relative Degradation and Interfacial Properties between Jute/Polypropylene and Jute/Natural Rubber Composites," Journal of Thermoplastics Composite Materials, Vol. 25, No. 5, 2010, pp. 665-681.

[7] I. A. T. Razera and E. Frollini, "Composites Based on Jute Fibers and Phenolic Matrices: Properties of Fibers and Composites," Journal of Applied Polymer Science, Vol. 91, No. 2, 2004, pp. 1077-1085. doi:10.1002/app.13224

[8] M. A. Khan, N. Haque, A. A. Kafi, M. N. Alam and M. Z. Abedin, "Jute Reinforced Polymer Composite by Gamma Radiation: Effect of Surface Treatment with UV Radiation," Polymer Plastic Technology and Engineering, Vol. 45, No. 5, 2006, pp. 607-613.

[9] M. A. Khan and M. M. Hassan, "Effect of $\gamma$-aminopropyl Trimethoxy Silane on the Performance of Jute-Polycarbonate Composite," Journal of Applied Polymer Science, Vol. 100, No. 6, 2006, pp. 4142-4147. doi:10.1002/app.23441

[10] M. A. Khan, M. M. Hassan and L. T. Drzal, "Effect of 2-Hydroxyethyl Mathacrylate(HEMA) on the Mechanical and Thermal Properties of Jute-Polycarbonate Composites," Composites Part A: Applied Science and Manufacturing, Vol. 36, No. 1, 2005, pp. 71-81. doi:10.1016/j.compositesa.2004.06.027

[11] M. A. Khan, G. Hinrichsen and L. T. Drzal, "Influence of Novel Coupling Agents on Mechanical of Jute Reinforced Polypropylene Composite," Journal of Material Science Letters, Vol. 20, No. 18, 2001, pp. 1711-1713. doi:10.1023/A:1012489823103

[12] H. U. Zaman, M. A. Khan, R. A. Khan, M. A. Rahman, L. R. Das and A. Mamun, "Role of Potassium Permanganate and Urea on the Improvement of the Mechanical Properties of Jute Polypropylene Composites," Fibers and Polymers, Vol. 11, No. 3, 2010, pp. 455-463. doi:10.1007/s12221-010-0455-4

[13] M. M. I. Khalil, M. E.-S. Naeem and A. E.-S. Gamil, “ $\gamma$ Irradiation Effects on the Thermal and Structural Characteristics of Modified, Grafted Polypropylene," Journal of Applied Polymer Science, Vol. 102, No. 1, 2006, pp. 506515. doi:10.1002/app.24236

[14] A. C. Karmaker and G. Hinrichen, "Processing and Characterization of Jute Fiber Reinforced Thermoplastic Po- 
lymers," Polymer-Plastic Technology and Engineering, Vol. 30, No. 5-6, 1991, pp. 609-618. doi:10.1080/03602559108019223

[15] M. A. Khan, G. Hinrichsen and L. T. Drzal, "Influence of Noble Coupling Agents on Mechanical Properties of Jute Reinforced Polypropylene Composites," Journal of Materials Science Letters, Vol. 20, No. 18, 2001, pp. 12111713. doi:10.1023/A:1012489823103

[16] R. A. Khan, M. A. Khan, S. Sultana, M. N. Khan, Q. T. H. Shubhra and F. G. Noor, "Mechanical, Degradation and Interfacial Properties of Synthetic Degradable Fiber Reinforced Polypropylene Composites," Journal of Reinforced Plastics and Composites, Vol. 29, No. 3, 2010, pp. 466-476. doi:10.1177/0731684408100699

[17] A. K. Mohanty and M. Misra, "Studies on Jute Composites a Literature Review," Polymer Plastic Technology and Engineering, Vol. 34, No. 5, 1995, pp. 729-792. doi:10.1080/03602559508009599

[18] M. A. Khan, C. Kopp and G. Hinrichsen, "Effect of Vinyl and Silicon Monomer on Mechanical and Degradation Properties of Bio-Degradable Jute-Biopol ${ }^{\circledR}$ Composite," Journal of Reinforced Plastics and Composites, Vol. 20, No. 16, 2001, pp. 1414-1429. doi:1106/RH67-0JVE-XX65-D39U

[19] A. A. Kafi, M. Z. Abedin, M. D. H. Beg, K. L. Pickering and M. A. Khan, "Study on the Mechanical Properties of Jute/Glass Fiber-Reinforced Unsaturated Polyester Hybrid Composite: Effect of Surface Modification by Ultraviolet Radiation," Journal of Reinforced Plastics and Composites, Vol. 25, No. 6, 2006, pp. 575-588. doi: $10.1177 / 0731684405056437$

[20] S. Mishra, A. K. Mohanty, L. T. Drzal, M. Misra, S. Parija, S. K. Nayak and S. S. Tripathy, "Studies on Mechanical Performance of Biofibre/Glass Reinforced Polyester Hybrid Composites," Composite Science and Technology, Vol. 63, No. 10, 2003, pp. 1377-1385. doi:10.1016/S0266-3538(03)00084-8 